\title{
BERGSON: INTUIÇÃO E MÉTODO INTUITIVO
}

\author{
J onas Gonçalves COELHO
}

- RESUM 0: Propomo-nos a mostrar que a intuição tal como aparece no pensamento de Bergson é tanto uma faculdade de conhecimento que se opõe à inteligência quanto um método filosófico constituído por procedimentos racionais, os quais a propiciam e enriquecem. Nesse sentido, ambos os aspectos da intuição estão intimamente ligados, sendo cada um imprescindível à compreensão do outro.

- PALAVRAS-CHAVE: Intuição; método; inteligência; instinto; conceito; imagem.

\section{Introdução}

Deleuze (1966) estabelece nos primeiros parágrafos de seu livro sobre Bergson, Le bergsonisme, o pressuposto fundamental de sua exposição, isto é, a tese de que a "intuição é o método do bergsonismo". Mais ainda, Deleuze considera que este método "rigoroso", que "tem suas regras estritas" tornando, assim, a filosofia uma "disciplina absolutamente precisa", é um dos métodos "mais elaborados da filosofia". Para Deleuze, este é um aspecto fundamental da obra de Bergson, pois é o "fio metódico da intuição" que permite compreender a relação entre as

1 Departamento de Ciências Humanas - Faculdade de Arquitetura, Artes e Comunicação - Unesp 17033-360 - Bauru - SP - Brasil. 
três noções que marcam as "grandes etapas da filosofia bergsoniana": duração, memória e élan vital. Deleuze não deixa dúvidas sobre o sentido de sua tese, ao estabelecer também aquilo que a intuição bergsoniana não é: "não é nem um sentimento, nem uma inspiração, nem uma simpatia confusa". Desse modo, em sua interpretação do pensamento de Bergson, Deleuze privilegia claramente o "racional" em detrimento do "irracional", sugerindo a incompatibilidade entre esses dois aspectos.

Ao colocar em primeiro plano a intuição em seu aspecto metódico e oferecer uma esclarecedora caracterização do método intuitivo bergsoniano, Deleuze parece ignorar ou, pelo menos, desconsiderar o fato de Bergson, com freqüência, referir-se à intuição como uma faculdade e definir o conhecimento intuitivo como "simpatia". Deleuze (1966, p.2) não explica por que Bergson dá ao seu método filosófico o nome de "intuição" e como é possível que a noção bergsoniana de duração, intuitiva por excelência, tenha, segundo o próprio Bergson, precedido em muito a teoria da intuição: poderia Bergson ter aplicado o método intuitivo antes de estabelecêlo? Esse último aspecto é reconhecido pelo próprio Deleuze ao afirmar que "bizarramente ... a duração permaneceria somente intuitiva, no sentido ordinário da palavra, se não houvesse a intuição como método, no sentido propriamente bergsoniano". Deleuze refere-se novamente aqui a dois sentidos para a intuição, o "ordinário" - 0 do senso comum - e o "propriamente bergsoniano" - o metódico -, privilegiando o segundo, ou seja, dando, também novamente, a entender - agora menos claramente - que a intuição em seu primeiro sentido, ou seja, como "sentimento", "inspiração" e "simpatia", não é admitida por Bergson.

Entendemos que há boas razões para discordar dessa segunda afirmação e postular que a intuição em Bergson não é apenas um método racional e preciso da filosofia mas também uma faculdade irracional de conhecimento. Parece-nos que esses dois aspectos não são excludentes, mais ainda, que o primeiro é incompreensível sem o segundo. Nesse sentido, as regras metódicas bergsonianas, as quais são na verdade um conjunto de procedimentos intelectuais, têm a função ou de propiciar a intuição para si e para os outros ou de legitimá-la, já que a intuição não depende do método, ou seja, ela pode ocorrer espontaneamente. Pretendemos, assim, mostrar que o método intuitivo de Bergson consiste no exercício exaustivo da inteligência a qual, voltando-se contra si própria, deixa de ser um impedimento à intuição, propiciando a "distração" necessária ao seu surgimento.

Procuraremos justificar essa interpretação, apontando, inicialmente, que há diversas referências de Bergson à intuição, em vários períodos de 
sua obra, nas quais se vê claramente que o filósofo não está referindo-se ao método intuitivo mas sim a uma faculdade ou a um modo de conhecimento que se opõe à inteligência. A seguir, veremos como é justamente essa oposição que explica a intuição como um método, na verdade, um método racional.

\section{Intuição ou inteligência}

São inúmeras as vezes em que Bergson se refere à intuição tanto como uma faculdade quanto como um modo de conhecimento distinto do intelectual, em que não caberia a interpretação metodológica.

Em um texto de 1922, Durée et simultanéité, o qual foi incluído posteriormente em Mélanges ${ }^{2}$ (1972), Bergson diz que algumas teses de Einstein sobre a velocidade dos tempos múltiplos e sobre a relação entre a simultaneidade, as sucessões e o ponto de vista dizem aquilo que 0 cientista "leu, por uma intuição genial, nas equações de Lorentz" (ME, p.59). Muitos anos antes, em um discurso pronunciado em 1895, Le bon sens et les études classiques, Bergson chama de "gênio" à "intuição superior ... necessariamente rara" a qual está presente "nas ciências e nas artes" e que consiste num "sutil pressentimento do verdadeiro e do falso, que tem podido descobrir entre as coisas, bem antes da prova rigorosa ou da experiência decisiva, das incompatibilidades secretas ou das afinidades insuspeitadas" (ME, p.361).

Em uma conferência proferida em 1911, L'intuition philosophique, a qual faz parte do livro La pensée et le mouvant (1993), Bergson, referindo-se à relação entre a intuição e a filosofia, afirma que o trabalho dos filósofos tem consistido em uma exaustiva tentativa de exprimir uma intuição: "Toda a complexidade de sua doutrina, que se estenderia ao infinito, é apenas a incomensurabilidade entre sua intuição simples e os meios de que dispunha para exprimi-la" (PM, p.119). Ainda nessa mesma conferência, Bergson surpreende-nos ao falar de um "poder intuitivo de negação", o qual se manifesta na filosofia pela rejeição definitiva de certas teses. Este é o "primeiro movimento do filósofo", o qual poderia até variar posteriormente em suas afirmações, mas sem variar "jamais" no que nega, e até mesmo essa variação pode ser explicada por esse "poder de negação imanente à intuição". Nesse sentido, Bergson diz que a in-

2 Os textos de Bergson que se apresentam de forma abreviada são Mélanges (ME), La pensée et le mouvant (PM) e L'évolution créatrice (EC). 
tuição se comporta em "matéria especulativa", tanto em seu início quanto em suas manifestações mais nítidas, como uma proibição, "ela proíbe", opondo-se até mesmo à razão científica:

Diante de idéias aceitas habitualmente, diante de teses que pareciam evidentes, de afirmações que até então haviam passado por científicas, ela sopra na orelha do filósofo a palavra: impossível. Impossível, mesmo quando os fatos e as razões parecem convidar a crer que isso é possível, real e certo. Impossível, porque uma certa experiência, talvez confusa mas decisiva, te diz por minha voz que ela é incompatível com os fatos que se alegam e com as razões que se dão, e que, por isso, estes fatos devem ter sido mal observados, estes raciocínios devem ser falsos. (PM, p.120)

Dentre as inúmeras vezes em que Bergson se refere à intuição como uma faculdade e um modo de conhecimento que se opõe ao da inteligência ou, conforme os termos de L'évolution créatrice, (1991), as "duas faculdades" que "a teoria do conhecimento deve tomar em consideração" (EC, p.159), destacamos as que se relacionam a Kant. Bergson ratifica a caracterização que Kant faz da inteligência no que diz respeito ao seu modo de operação, seu campo legítimo de aplicação e aos seus limites, mas diverge ao postular a existência de "uma outra faculdade, capaz de uma outra espécie de conhecimento" (PM, p.86). Conforme Bergson afirma em L'intuition philosophique, o próprio Kant provava, por "argumentos decisivos, que nenhum esforço dialético jamais nos introduzirá no além" (PM, p.141), que, pela dialética, a metafísica é impossível. Kant reconhecia, também, segundo os termos de uma outra conferência de Bergson de 1911, La perception du changement - e esta seria uma das "idéias mais importantes e mais profundas da Crítica da razão pura" - que se a "metafísica é possível é por uma visão" (PM, p.154), ou seja, por meio de uma "intuição superior", a "intuição intelectual", enfim, a "percepção da realidade metafísica" (PM, p.154). Assim, para Kant, uma "metafísica eficaz seria necessariamente uma metafísica intuitiva" (PM , p.141), embora acrescente que a metafísica é impossível justamente pela inexistência da faculdade que propicia esse conhecimento supra-intelectual, a intuição. Esse é, para Bergson, o erro de Kant: "toda a filosofia que eu exponho, desde meu primeiro Essai, afirma contra Kant a possibilidade de uma intuição supra-sensível ... supra-intelectual..." (ME, p.1322).

0 papel que Bergson atribui à intuição na arte também não pode ser caracterizado como metódico. Para o filósofo, as diversas artes constituemse como uma "visão mais direta da realidade" (PM, p.152), um exemplo privilegiado de expressão de uma intuição apreendida pelos artistas os 
quais são "homens cuja função é justamente ver e nos fazer ver o que nós não percebemos naturalmente" (PM, p.149), mostrando que é possível uma "extensão das faculdades de perceber" (PM, p.150). Os artistas são reveladores, à medida que são capazes de mostrar, "fora de nós e em nós, coisas que não impressionavam explicitamente os nossos sentidos e nossa consciência" (PM, p.149), percebendo "na natureza aspectos que nós não observávamos". 0 artista isola e fixa aquilo que ele viu na realidade e que nós, agora, "não poderemos nos impedir de aperceber". E se nós os admiramos é porque já havíamos percebido "alguma coisa do que eles nos mostram", ou seja, "nós havíamos percebido sem perceber" (PM, p.149).

Contra a afirmação de Deleuze, segundo a qual a intuição em Bergson "não é nem um sentimento, nem uma inspiração, nem uma simpatia confusa", não podemos deixar de observar que Bergson propõe freqüentemente o termo "simpatia" tanto para definir quanto para justificar o uso da palavra intuição a qual: consiste num colocar-se "simpaticamente no interior da realidade" (ME, p.1197); é "a simpatia pela qual nos transportamos para o interior de um objeto para coincidir com o que ele tem de único e, conseqüentemente, de inexprimível" (PM, p.181); é um modo de conhecimento que pretende se liberar "de todo pressuposto de relação e de comparação para simpatizar com a realidade" (EC, p.177). Ao usar uma palavra que remete à tendência, instinto, sentimento, para caracterizar a intuição, Bergson remete-nos a um significado "irracional", como aparece mais claramente em uma referência à possibilidade de um conhecimento não intelectual de outras consciências: "A simpatia e a antipatia irrefletidas, tão freqüentemente proféticas, são um testemunho da interpenetração possível das consciências humanas" (PM , p.28).

Nesse sentido, é bastante sugestivo o fato de Bergson definir o instinto que também opõe à inteligência - "a inteligência e o instinto implicam duas espécies de conhecimento radicalmente diferentes" (EC, p.129) - em termos de simpatia. Para o filósofo, é a noção de simpatia que melhor define o instinto: "Instinto é simpatia" (EC, p.177). É nos fenômenos de "simpatia e antipatia irrefletidos" que podemos apreender, embora de maneira "muito mais vaga e demasiado penetrada" de inteligência, algo do que ocorre "na consciência de um inseto que age por instinto" (EC, p.177). Bergson chega mesmo a usar a palavra intuição como sinônimo de instinto, associado à simpatia, ao dizer que o inseto "apreende por dentro ... por uma intuição (vivida mais que representada) que se assemeIha sem dúvida ao que chamamos de simpatia adivinhadora" (EC, p.157).

Essas duas formas de conhecimento correspondem às duas linhas evolutivas divergentes e bem-sucedidas, o instinto e a inteligência, os 
quais estiveram provavelmente juntos na origem, dando lugar um ao outro no decorrer da evolução da vida, mas sem desaparecer naquela linha evolutiva onde não prevaleceu. É sob esse ângulo que Bergson (1992, p.265) afirma em Les deux sources de la morale et de la religion que "em torno do instinto animal, persistiu uma franja de inteligência" enquanto "a inteligência humana foi aureolada pela intuição". Esse instinto que sobrevive no homem como intuição é caracterizado como uma vaga nebulosidade em torno do núcleo luminoso da inteligência: "A consciência no homem é sobretudo inteligência ... a intuição acha-se completamente sacrificada à inteligência" (EC, p.267). A ssim, a intuição é o instinto acrescido de consciência e de reflexão - atributos da inteligência - , ampliado e aprimorado, graças à presença da inteligência: "o instinto que se tornou desinteressado, consciente de si mesmo, capaz de refletir sobre seu objeto e de 0 ampliar indefinidamente" (EC, p.178). É a inteligência que fornece à intuição o "arranco" que a eleva acima do objeto específico de interesse prático, que a fazia permanecer "sob a forma de instinto" (EC, p.179). Desse modo, a intuição que está presente no homem de forma "vaga e sobretudo descontínua" acaba por constituir-se como o "lampejo" que lança luz sobre o que é obscurecido pela inteligência: "É uma lâmpada quase extinta, que só se reacende vez por outra, por alguns instantes apenas" (EC, p.268).

A o apresentar algumas dentre as inúmeras referências que Bergson faz à intuição como uma faculdade que se opõe à inteligência, como um modo de conhecimento que não pode ser caracterizado como metódico, não perdemos de vista o fato de que a intuição é para Bergson também um método preciso da filosofia. Entendemos que esses dois aspectos estão intimamente relacionados e que o segundo não pode ser compreendido sem o primeiro.

\section{Intuição e inteligência}

No ensaio Introduction à la métaphysique, referindo-se à problemática do conhecimento, Bergson destaca um aspecto que considera comum aos filósofos: eles distinguem "duas maneiras profundamente diferentes de conhecer uma coisa" (PM , p.177) e isso independentemente de as considerarem legítimas ou possíveis. Uma dessas formas de conhecimento consiste em manter-se no relativo, ou seja, em permanecer fora do objeto, rodeando-0, assumindo um "ponto de vista" sobre ele e se utilizando de "símbolos" para exprimi-lo; enfim, o conhecimento relativo 
é aquele que "altera a natureza de seu objeto" (ME, p.774). Já o outro modo de conhecimento, 0 "conhecimento absoluto" ou o "conhecimento do absoluto", caracteriza-se por entrar no objeto, apreendê-lo, captá-lo "por dentro, nele mesmo, em si" (PM , p.178), ou seja, não se parte do sujeito, excluindo-se, assim, o "ponto de vista" e a mediação de "símbolos".

0 próprio Bergson mantém essa distinção que encontra na tradição filosófica, considerando que há efetivamente dois modos de conhecimento. Para o filósofo, o conhecimento relativo, estático, por conceitos, que envolve uma "separação entre aquele que conhece e o que é conhecido" (ME, p.773), é o intelectual, o qual, embora se justifique pragmaticamente, é teoricamente limitado, sendo o gerador de problemas filosóficos aparentemente insolúveis. 0 conhecimento que toca 0 absoluto, que tem a virtude de resolver os problemas gerados pelo anterior, é o intuitivo. Este consiste num modo de apreensão imediata, na identificação, na coincidência com o particular, com o que não é, portanto, traduzível em conceitos, constituindo-se como uma visão direta da real idade: "consciência imediata, visão que não se distingue do objeto visto, conhecimento que é contato e mesmo coincidência" (PM, p.27).

Embora 0 absoluto possa ser apreendido intuitivamente, possa ser pensado sem a mediação do conceito e do espaço a ele relacionado, isso só ocorre excepcionalmente, pois, conforme Bergson nos diz já na primeira frase do Essai sur les données immediates de la conscience (1988), como seres inteligentes que somos, "pensamos quase sempre no espaço" (p.vii). Esse pensamento espacializado é expresso e forjado pela linguagem que, por meio de seus símbolos, os conceitos, se constitui como 0 instrumento mais imediato da inteligência. Pelo fato de as palavras serem o meio imprescindível de expressão do pensamento - "Exprimimonos necessariamente por palavras" (p.vii) -, há uma incomensurabilidade entre a intuição e os meios disponíveis para exprimi-la: "Essa intuição, se não nos comunicará jamais completamente, porque a linguagem que se nos fala, tão especiais e tão apropriados que se suponha seus signos, não pode exprimir senão as semelhanças, e é de uma diferença que se trata" (ME, p.611).

Para Bergson, o método intelectual opera sempre dos conceitos para a realidade, ampliando a sua generalidade sempre que se aplica a um novo objeto. Esses conceitos "rígidos e pré-fabricados" (PM, p.213) funcionam como gavetas ou roupas feitas, que escolhemos para colocar o novo objeto: "Será esta, essa ou aquela coisa? E "esta", "essa" ou "aquela" coisa, para nós, é sempre o já concebido, o já conhecido" (EC, p.48). Esses conceitos "de origem intelectual" são "imediatamente claros" para 
quem "pode esforçar-se o suficiente", claros à medida que se "nos apresentam, simplesmente numa nova ordem, idéias elementares que já possuímos" (PM, p.31). É nesse sentido que a inteligência, "não encontrando no novo mais do que no antigo, sente-se em terra conhecida; ela está à vontade, ela 'compreende'" (PM, p.31).

$M$ as essa compreensão, propiciada pela inteligência e seus conceitos, não advém da apreensão efetiva do absoluto que só pode ser dada pela intuição, um modo de conhecimento incomum, não "natural" na condição humana, e que pode ocorrer tanto espontaneamente, como no caso da intuição artística, quanto ser preparado por um percurso analítico. E são justamente as considerações de Bergson a respeito da intuição artística que nos fornecem a chave para a compreensão da função do método intuitivo.

Bergson considera que a ampliação do campo perceptivo do artista está relacionada ao fato de ele ser um "distraído", um desapegado em relação às exigências do viver e do agir, pois, afinal, "as necessidades da ação tendem a limitar o campo da visão" (PM, p.151). À medida que seus sentidos e consciência "são menos aderentes à vida", eles são capazes de olhar uma coisa e a verem "por ela, e não mais por eles", ou seja: "Eles não percebem mais simplesmente em vista do agir; eles percebem por perceber - por nada, por prazer" (PM, p.152). As diversas artes constituem-se como uma "visão mais direta da realidade", e é porque "0 artista pensa menos em utilizar sua percepção que ele percebe um maior número de coisas" (PM, p.152). Desse modo, o artista é um privilegiado por possuir uma inclinação espontânea à distração, a qual Ihe permite essa apreensão direta da realidade. É esse mesmo resultado, "uma percepção mais completa da realidade", que pode ser alcançado por um esforço metódico que consista num "certo deslocamento de nossa atenção". 0 que significa que o método intuitivo consiste em - esse é um outro aspecto seu - "desviar esta atenção do lado praticamente interessante do universo e de a retornar para o que, praticamente, não serve para nada" (PM , p.153). É partindo desse princípio que Bergson nos diz que a existência no homem "de uma faculdade estética ao lado da percepção normal" demonstra que "um esforço desse gênero não é impossível" (EC, p.178). Isso não quer dizer que a atividade artística envolva um esforço que possa ser caracterizado como metódico, ou seja, como aplicação de regras propiciadoras de um certo tipo de conhecimento, mas sim que a atividade do filósofo deve consistir numa "pesquisa orientada no mesmo sentido que a arte" (PM, p.159), isto é, deve ser orientada para produzir a "distração" necessária à intuição. Consideremos mais detalhadamente esse aspecto. 
Referindo-se claramente ao método filosófico que propõe, Bergson diz que a intuição não é nem "uma contemplação passiva do espírito por ele mesmo" nem "um sonho de onde ele sai dando suas visões para as coisas vistas", mas que "pode ser tão precisa quanto os mais precisos dentre os procedimentos científicos, tão incontestável quanto os mais incontestáveis dentre eles" (ME, p.611). Às vezes, parece não haver em Bergson a coincidência entre o método filosófico e a intuição, como quando o filósofo afirma que o método "compreende dois momentos e implica dois passos sucessivos do espírito": primeiro, "um estudo científico do entorno da questão" e só após viria "a operação propriamente filosófica", ou seja, a intuição, que Bergson define como "um esforço muito difícil e muito penoso pelo qual se rompe com as idéias preconcebidas e os hábitos intelectuais totalmente feitos, para se recolocar simpaticamente no interior da realidade" (ME, p.1197). Mas, considerando mais atentamente, podemos observar que o primeiro passo metodológico, o estudo científico, tem freqüentemente o objetivo de mostrar o caráter metafísico das interpretações científicas, podendo, assim, ser visto como um aspecto do esforço de rompimento com os preconceitos e hábitos intelectuais impeditivos da apreensão direta do real. Como nos diz Bergson em outro momento, a intuição "consiste em retomar contato com uma realidade concreta sobre a qual as análises científicas nos têm fornecido tantos ensinamentos abstratos: para isso se auxiliará de início dessas próprias análises" (ME, p.611) Ou ainda,

a intuição poderá fazer-nos captar o que os dados da inteligência têm no caso de insuficiente e deixar-nos entrever o meio de os completar. Por um lado, de fato, ela utilizará o mecanismo mesmo da inteligência para mostrar como os esquemas intelectuais não encontram mais aqui sua exata aplicação, e, por outro, por seu trabalho próprio, ela nos irá sugerir pelo menos o sentimento vago do que é preciso pôr em lugar dos esquemas intelectuais. (EC, p.178)

Depreende-se daí que o método intuitivo bergsoniano compreende dois aspectos fundamentais: 0 aspecto negativo, que consiste tanto na denúncia do caráter ilusório das produções da inteligência quanto na identificação da origem de certos problemas filosóficos; e 0 aspecto positivo, que diz respeito à solução do problema, a qual envolve a intuição propriamente dita, a apreensão imediata do real. Deve-se considerar, ainda, que esses dois aspectos estão intimamente relacionados. Se por um lado a crítica ao entendimento cria as condições propícias para o surgimento da intuição, por outro, não se pode ignorar que as objeções à inteligência não podem ser dissociadas da resposta proporcionada pela intuição aos 
problemas formulados pela própria inteligência, incluindo aí a desqualificação destes. Assim, embora a crítica às ilusões da inteligência não possa ser operada sem a mediação do entendimento, ela depende da intuição, tanto em sua forma negativa, "poder intuitivo de negação", quanto em sua contrapartida positiva. Decorre daí que a intuição "fugidia", que é no início uma "Iuz vacilante e fraca" que penetra "na escuridão da noite em que a inteligência nos deixa" só iluminando "seu objeto de longe em longe" (EC, p.268), ganha com essa crítica, com esse exercício do entendimento que tanto a sustenta quanto a enriquece.

Entendemos que para Bergson a intuição é tanto uma forma de conhecimento, que pode apenas esporadicamente e em circunstâncias especiais acontecer espontaneamente, quanto pode ser propiciada por meio de certos procedimentos analíticos. Não se trata de um empreendimento fácil, pois envolve "um esforço muito difícil e muito penoso pelo qual se rompe com as idéias preconcebidas e os hábitos intelectuais totalmente feitos" (ME, p.1197) para criar idéias que começam "ordinariamente por serem obscuras, seja qual for nosso esforço de pensamento" (PM, p.31). Isso porque, como a intuição só pode ser "comunicada por meio da inteligência" esta deverá "para lograr transmitir-se, cavalgar sobre as idéias" (PM, p.42). Desse modo, para que uma "idéia radicalmente nova e absolutamente simples, que capta mais ou menos uma intuição" (PM , p.31), torne-se clara, é necessário um trabalho de "longo prazo". Tal idéia, que a princípio nos aparece como "incompreensível" e "obscura", "dissipará as obscuridades" presentes nos "diversos departamentos de nosso conhecimento" e, ao dissolver os "problemas que julgamos insolúveis", ela "se beneficiará do que tiver feito por esses problemas" (PM, p.32). Assim, a aplicação da idéia intuitiva não apenas a torna mais clara, mas também, à medida que seja capaz de solucionar esses problemas, ela torna-se legítima: "sua capacidade para resolver as oposições delas suprimindo os problemas é, a meu ver, a marca exterior pela qual a intuição verdadeira do imediato se reconhece" (ME, p.771). Bergson pretende, então, que uma idéia intuitiva se torne mais inteligível à proporção que se a aplica, e ela se mostra fecunda quando soluciona problemas "insolúveis".

Cada um deles, intelectual, Ihe comunicará um pouco de sua intelectualidade. Assim, intelectualizada, ela poderá ser apontada novamente para os problemas que a servirão, depois de se terem servido dela: dissipará, ainda mais, a obscuridade que os envolvia, e tornar-se-á ela própria mais clara ... Estas podem começar por ser interiormente obscuras; mas a luz que projetam ao redor voltaIhes por reflexão, penetra-as cada vez mais profundamente; e elas possuem então o duplo poder de aclarar em torno delas e aclarar-se a si mesmas (PM, p.32). 
Mas como expressar essas idéias tendo em vista que, segundo o próprio Bergson, a intuição não pode "se encerrar numa representação conceitual" (PM, p.189)? Para o filósofo, o método intuitivo consiste na inversão do "percurso natural do trabalho de pensamento, para se colocar imediatamente, por uma dilatação do espírito, na coisa que se estuda, enfim, para ir da realidade aos conceitos" (PM, p.206), pois, como nos diz o próprio filósofo, "a intuição, como todo pensamento, acaba por se alojar em conceitos" (PM, p.31). Embora os conceitos sejam indispensáveis à metafísica, ela deve abandonar os conceitos prontos que estão à disposição, os quais "manejamos habitualmente", e criar "conceitos diferentes": a "filosofia consiste o mais freqüentemente não em optar entre conceitos, mas em criá-los" (ME, p.503). Devemos, assim, "afastar os conceitos já prontos", procurando, a partir da "visão direta do real", criar "conceitos novos, que deveremos formar para nos exprimir" e que serão "talhados na exata medida do objeto" (PM, p.23). Trata-se, então, "de criar completamente, para um objeto novo, um novo conceito, talvez um novo método de pensar" (EC, p.48). Esse novo conceito que devemos "talhar" para cada novo objeto deve ser apropriado somente para ele, de tal modo "que se pode dificilmente dizer que seja ainda um conceito, pois somente se aplica a uma única coisa" (PM, p.197). Bergson caracteriza esses conceitos intuitivos como representações "flexíveis, móveis, quase fluidas, sempre prontas a se moldarem sobre as formas fugidias da intuição" (p.188), ou, ainda nesse mesmo sentido, diz que se trata de "conceitos que se modelam e se remodelam sem cessar sobre os fatos, conceitos fluidos como a própria realidade" (ME, p.501).

0 que parece fluido, de fato, são os significados desses conceitos que não podem ser expressos pelos conceitos tradicionalmente utilizados pela inteligência. Daí por que Bergson nos remete a um outro modo mais fecundo de expressão do pensamento, do dado intuitivo: a imagem. Embora as imagens não sejam a intuição, elas derivam imediatamente dela, aproximam-se da intuição mais que os conceitos, podendo ajuntarse a eles para fornecer a intuição. Em L'intuition philosophique, o filósofo define a imagem como "quase matéria, pois se deixa ainda ver, e quase espírito, pois não se deixa tocar" (PM, p.130). Essas imagens, que derivam da intuição, são indispensáveis para apreendê-la. Elas são necessárias para "obter o signo decisivo, a indicação da atitude a tomar e do ponto para onde olhar" (p.130). Nesse sentido, Bergson considera que as imagens são superiores aos conceitos, como modo de apreensão e expressão do dado intuitivo. 
Mas o que chegaremos a apreender e fixar é uma certa imagem intermediária entre a simplicidade da intuição concreta e a complexidade das abstrações que a traduzem, imagem fugidia e evanescente, que ronda, talvez desapercebida, 0 espírito do filósofo, que o segue como sua sombra por entre os meandros de seu pensamento, e que, se não é a própria intuição, dela se aproxima muito mais do que a expressão conceitual necessariamente simbólica, à qual a intuição tem de recorrer para fornecer "explicações". Observemos bem esta sombra: melhor, para nos inserirmos nela, veremos de novo, na medida do possível, aquilo que 0 adivinharemos, a atitude do corpo que a projeta. E se nos esforçarmos para imitar esta atitude, ou melhor, para nela nos inserir, nós veremos, na medida do possível, aquilo que o filósofo viu. (PM, p.119)

Bergson, todavia, postula também que mesmo essas imagens "que se podem apresentar ao espírito do filósofo quando ele quer expor seu pensamento a outro" (PM, p.186) não representam, não reproduzem o absoluto; elas são incapazes de transmiti-lo àqueles que não são capazes de se dar a intuição a si mesmos. Aquele que teve a intuição pode, por meio das imagens, "provocar um certo trabalho que tende a entravar, na maior parte dos homens, os hábitos de espírito úteis à vida" (PM , p.185), colocar a consciência na "atitude que deve tomar para fazer o esforço requerido e chegar, ela própria, à intuição" (PM, p.186). Embora nenhuma imagem substitua a intuição, muitas delas "diversificadas, emprestadas à ordem de coisas muito diferentes, poderão, pela convergência de sua ação, dirigir a consciência para o ponto preciso em que há uma intuição a ser apreendida" (PM, p.185). Elas podem realizar em conjunto aquilo que não podem individualmente, ou seja, sugerir indiretamente a intuição.

Escolhendo imagens tão disparatadas quanto possível, impediremos que uma qualquer dentre elas venha usurpar o lugar da intuição que ela está encarregada de evocar, pois, neste caso, ela seria imediatamente expulsa por suas rivais. Fazendo que todas exijam de nosso espírito, apesar de suas diferenças de aspecto, a mesma espécie de atenção e, de alguma forma, o mesmo grau de tensão, acostumamos pouco a pouco a consciência a uma disposição bem particular e bem determinada, precisamente aquela que deverá adotar para aparecer a si mesma sem véu. (PM, p.185)

Mas não podemos perder de vista que se, por um lado, a utilização de imagens pode ser considerada como um dos procedimentos do método intuitivo, o qual contribui para sugerir a intuição àquele que não a tem, por outro, quem as propõe só as pode ter escolhido a partir de uma intuição existente que norteia essa escolha; afinal, não são quaisquer imagens que servem a esse objetivo. 0 que indica novamente que a intuição é, sob esse aspecto, irredutível ao método intuitivo. 


\section{Conclusão}

Procuramos mostrar anteriormente que a intuição em Bergson deve ser considerada sob um duplo aspecto, como faculdade e modo de conhecimento não intelectual e como método racional. Entendemos que não poderíamos terminar nosso trabalho sem retomar uma questão que colocamos logo no início: a escolha do termo intuição para um método que consiste em procedimentos intelectuais.

Na segunda parte da introdução a La pensée et le mouvant, Bergson refere-se à escolha da palavra "intuição", para definir seu método filosófico. Diz ter hesitado durante muito tempo diante desse termo, embora o considere o "mais apropriado" para designar o "modo de conhecimento" por ele proposto. Sua hesitação, diz ainda o filósofo, deve-se à confusão que o termo "intuição" propicia. Bergson não quer ser confundido com outros filósofos - Shelling, Schopenhauer, por exemplo - que opuseram "mais ou menos" a "intuição à inteligência", que ao "sentirem a insuficiência do pensamento conceitual para atingir o fundo do espírito ... falaram de uma faculdade supra-intelectual de intuição". Para Bergson, essa intuição "está ligada à inteligência", apenas com diferença de substituir seus conceitos "por um conceito único que os resume a todos e que é, conseqüentemente, sempre o mesmo, seja qual for o nome que the dermos". Tratar-se-ia de formas de panteísmo que ao darem, "antecipadamente, num princípio que é o conceito dos conceitos, todo o real e todo 0 possível", é capaz de "explicar dedutivamente todas as coisas" (PM, p.25).

Contra essa intuição, que se confunde com a inteligência, Bergson propõe um método que consiste em recuperar a "realidade em sua essência", enfim, uma "metafísica verdadeiramente intuitiva que seguisse todas as ondulações do real", que não abarca "de uma só vez a totalidade das coisas" mas que dá de cada uma delas "uma explicação que se adaptaria exatamente, exclusivamente a ela" (PM, p.25). Sob esse aspecto, compreende-se a afirmação bergsoniana segundo a qual se pode ir da intuição à inteligência e que "da inteligência não se passará jamais à intuição" (EC, p.268); afinal de contas, como tivemos a oportunidade de mostrar, com os conceitos prontos da inteligência, não podemos representar a intuição, e que é a partir da intuição que os significados dos conceitos deverão ser gradativamente constituídos.

Mas isso não significa uma contradição com a afirmação anterior, segundo a qual o método intuitivo bergsoniano consiste em procedimentos racionais, ou seja, que podemos passar da inteligência à intuição? $\mathrm{Não}$, se considerarmos que um dos aspectos do método intuitivo se ca- 
racteriza pela utilização da inteligência contra ela própria, buscando uma apreensão mais direta possível dos fatos, seu verdadeiro significado, denunciando as conclusões que embora metafísicas se pretendem científicas, criando, assim, o campo propício para o surgimento da intuição propriamente dita, cuja representação envolverá novamente um grande esforço por parte da inteligência. É nesse sentido que devemos compreender as seguintes considerações de Bergson:

Intuição e intelecto não se opõem um ao outro, salvo aí onde a intuição recusa tornar-se mais precisa pela entrada em contato com os fatos cientificamente estudados, e aí onde 0 intelecto, em lugar de se limitar à ciência propriamente dita (isto é, ao que pode ser inferido a partir dos fatos ou provado pelo raciocínio), combina com isto uma metafísica inconsciente e inconsistente que se reclama em vão de pretensões científicas. (ME, p.938)

COELHO, J. G. Bergson: intuition and intuitive method. Trans/Form/Ação (São Paulo), v.21-22, p.151-164, 1998-1999.

- ABSTRACT: Our purpose is to show that intuition, according to Bergson's thought, is both a knowledge faculty that opposes intelligence and a philosophical method constituted by rational procedures which provides and enriches it. In this way, both aspects of intuition are intimately connect and indispensable to the understanding of each other.

- KEYWORDS: Intuition; method; intelligence; instinct; concept; image.

\section{Referências bibliográficas}

BERGSON, H. M élanges. Paris: PUF, 1972.

. Essai sur les données immédiates de la conscience. 3.ed. Paris: PUF, 1988. . L'évolution créatrice. 5.ed. Paris: PUF, 1991.

. Les deux sources de la morale et de la religion. 5.ed. Paris: PUF, 1992.

. La pensée et le mouvant. 4.ed. Paris: PUF, 1993.

DELEUZE, G. Le bergsonisme. Paris: PUF, 1966. 